\title{
Proteomic identification of potential cancer markers in human urine using subtractive analysis
}

\author{
HOLGER HUSI ${ }^{1}$, RICHARD J.E. SKIPWORTH ${ }^{2}$, ANDREW CRONSHAW ${ }^{3}$, \\ KENNETH C.H. FEARON ${ }^{2 *}$ and JAMES A. ROSS ${ }^{2 *}$ \\ ${ }^{1}$ Institute of Cardiovascular and Medical Sciences, University of Glasgow, Glasgow, G12 8QQ; ${ }^{2}$ School of Clinical Sciences, \\ ${ }^{3}$ School of Biological Sciences, University of Edinburgh, Edinburgh, EH16 4SB, UK
}

Received November 21, 2015; Accepted December 27, 2015

DOI: $10.3892 /$ ijo.2016.3424

\begin{abstract}
Urine is an ideal medium in which to focus diagnostic cancer research due to the non-invasive nature and ease of sampling. Many large-scale proteomic studies have shown that urine is unexpectedly complex. We hypothesised that novel diagnostic cancer biomarkers could be discovered using a comparative proteomic analysis of pre-existing data. We assembled a database of 100 published datasets of 5,620 urinary proteins, as well as 46 datasets of 8,620 non-redundant proteins derived from kidney and blood proteome analyses. The data were then used to either subtract or compare molecules from a novel urinary proteome profiling dataset that we generated. We identified 1,161 unique proteins in samples from either cancer-bearing or healthy subjects. Subtractive analysis yielded a subset of 44 proteins that were found uniquely in urine from cancer patients, 30 of which were linked previously to cancer. In conclusion, this approach is useful in discovering novel biomarkers in tissues where unrelated profiling data is available. Only a limited disease-specific novel dataset is required to define new targets or substantiate previous findings. We have shared this discovery platform in the form of our Large Scale Screening Resource database, accessible through the Proteomic Analysis DataBase portal (www.PADB.org).
\end{abstract}

Correspondence to: Dr Holger Husi, Institute of Cardiovascular and Medical Sciences, University of Glasgow, ICAMS, MVLS, B2-21 Joseph Black Building, University Place, Glasgow, G12 8QQ, UK E-mail: holger.husi@glasgow.ac.uk

Professor James A. Ross, School of Clinical Sciences, University of Edinburgh, Tissue Injury and Repair Group, FU501, Chancellors Building, 49 Little France Crescent, Edinburgh, EH16 4SB, UK E-mail: j.a.ross@ed.ac.uk

*Joint senior authorship

Key words: urine, mass spectrometry, cancer marker, meta-analysis

\section{Introduction}

Screening of human tissues for cancer biomarkers is an important task in cancer diagnosis and treatment, which is hindered by the complexity of the sample systems studied. A less complex system such as urine is a preferred medium to screen for protein or peptide biomarkers due to the non-invasive sampling of patients, ease of sampling and the unrestricted quantities obtainable. Urine is relatively stable in terms of protein/peptide composition and fragmentation compared with other bodily fluids such as serum, where proteolytic degradation by endogenous proteases has been shown to occur during or after sample collection (1).

Several investigations have been published describing the urinary peptidome and proteome (as well as biomarker discoveries for several diseases) using methodologies ranging from traditional 2D gel electrophoresis alone (2), or coupled with mass spectrometry (2-DE-MS) (3), immunohistochemistry (4), liquid chromatography mass spectrometry (LC-MS) (5), and surface enhanced laser desorption ionisation-time of flight mass spectrometry (SELDI-TOF-MS) (6-9).

The proteomic screening of urine for potential cancer markers has shown several proteins to be differentially present in ovarian cancer (10). Bladder cancer biomarkers constitute a different non-overlapping set of molecules (11-13), as do potential biomarkers for upper gastrointestinal cancers (9). An improvement in the reliability of diagnostic tests is to employ more than one biomarker synchronously $(9,14)$. For example, one previous study employed an antibody-based array of 810 different antibodies to define peptide patterns in urine associated with cancer (15). A different approach was used successfully in recent years, combining urinary mass spectroscopy with protein/peptide pattern analysis to identify kidney disease (16).

There is a clear need to collect and cross-correlate the wealth of data published in the scientific literature. Currently, there are a number of urinary databases available. The majority consist of lists of identified proteins derived from tryptic digests analysed by liquid chromatography tandem mass spectrometry (LC-MS/MS), such as the Max-Planck Unified Proteome Database (MAPU) (17) and Sys-BodyFluid (18). More recently, a urinary database combining chromatographic reverse-phase retention times and $\mathrm{m} / \mathrm{z}$ values has been established (19). 
However, there is no database available which integrates all of the data. In order to fill this gap, we have assembled datasets from 100 urinary proteomic studies in our novel proteomic database termed the Large Scale Screening Resource (LSSR). LSSR is accessible and downloadable through the Proteomic Analysis DataBase (PADB) portal at www.PADB.org.

In this study, we explore the possibility of discovering novel cancer-associated molecular markers in human urine by subtractive analysis using a novel dataset of the human cancer urinary proteome [derived from patients with upper gastrointestinal (GI) cancer] and comparing it to non-cancer urinary datasets.

\section{Materials and methods}

Materials. Tris/Tricine peptide gels, gel-running buffers, CM and IMAC resins, and chromatography buffers were from Bio-Rad (Hemel Hempstead, UK). All other chemicals were obtained from Sigma-Aldrich (Gillingham, UK).

Sample collection. Urine samples were obtained from upper GI cancer patients $(n=41)$ and non-cancer controls $(n=21)$ as described previously (9). Summary participant demographics are shown in Table I. Participant age ranged between 21 and 84 (control group), and 43 and 82 (cancer group). Random morning urine samples were collected over a time period of 2 years. Cancer urine samples were collected prior to surgery if the patient was being considered for resection. All procedures were approved by the local research ethics committee, and written informed consent was obtained. The study conformed to the standards set by the Declaration of Helsinki. All urine samples were kept at $-40^{\circ} \mathrm{C}$ for short-term or $-80^{\circ} \mathrm{C}$ for longterm storage.

Chromatographic enrichment of urine proteins and peptides, and sample preparation. Aliquots of $0.5 \mathrm{ml}$ from individual cancer or control urine samples was added to either $30 \mu \mathrm{l}$ CM10 ( $\mathrm{n}=33$ cancer urines, $\mathrm{n}=8$ control urines) or $30 \mu 1$ IMAC30 $\left(\mathrm{Cu}^{2+}\right.$-chelated $)(\mathrm{n}=21$ cancer urines, $\mathrm{n}=19$ control urines) spin column resin (Bio-Rad) and $0.75 \mathrm{ml}$ binding buffer (either $0.1 \mathrm{M} \mathrm{NaH}_{3} \mathrm{C}_{2} \mathrm{O}_{2} \mathrm{pH} 4.0$ for $\mathrm{CM}$ resin, or $0.1 \mathrm{M}$ $\mathrm{NaHPO}_{4} \mathrm{pH} 7.0$ including $0.5 \mathrm{M} \mathrm{NaCl}$ for IMAC30 resin) and incubated for $1 \mathrm{~h}$ at room temperature under constant agitation. Sample and resin combinations were chosen based on independent analyses using peak stratification by SELDI mass spectrometry (9). Unbound material was removed and the resin washed four times with $0.3 \mathrm{ml}$ binding buffer. Bound material was separated by electrophoresis on a $16.5 \%$ Tris-Tricine gel (Bio-Rad), and gel bands in the region of 2-10 kDa were excised after Coomassie staining (BioSafe Coomassie; Bio-Rad). The molecular mass range of 2-10 kDa was selected since many urinary proteins are derived from proteolytic processing and urinary shedding as described (20). Additionally, we previously observed potential urinary cancer markers in this mass range (9).

LC-MS/MS mass spectrometry. Proteins and peptides from gel bands were digested in situ with trypsin. The resulting peptides were eluted with acetonitrile (ACN), and analysed by LC-MS/ MS (21). The LC-MS system consisted of an Agilent 1200
Series HPLC (Agilent Technologies, Yarnton, UK) with a Kasil sealed fused silica pre-column (Next Advance, New York, NY, USA) packed to a length of $\sim 3 \mathrm{~cm}$ with Pursuit C18, $5 \mu \mathrm{m}$ particle size (Varian, Crawley, UK) and PicoTip Emitter analytical column PF 360-75-15-N-5 (New Objective, Woburn, MA, USA) packed to a length of $\sim 20 \mathrm{~cm}$ with Pursuit C18, $5 \mu \mathrm{m}$ particle size (Varian). The column was equilibrated with solvent A $(0.1 \%$ formic acid in $2.5 \%$ acetonitrile) and eluted with a linear gradient from 0 to $10 \%$ over 6 to $8 \mathrm{~min}$; from 8 to $60 \%$ over 8 to $35 \mathrm{~min}$; from 60 to $100 \%$ over 35 to $40 \mathrm{~min}$; solvent B (0.1\% formic acid, $0.025 \%$ TFA in $90 \%$ acetonitrile) over $45 \mathrm{~min}$ at a flow rate of $5 \mu \mathrm{l} / \mathrm{min}$. The LTQ mass spectrometer (Thermo Scientific, Epsom, UK) was fitted with a NanoLC ESI source. Data-dependent acquisition was controlled by XCalibur software. Fragmentation spectra were then processed by XCalibur and BioWorks software (Thermo Fisher Scientific, Loughborough, UK) and submitted to the Mascot search engine (Matrix Science, London, UK) using UniProt/SwissProt (release May 2011, Homo sapiens, 18055 sequences) as the reference database. Mascot search parameters were: enzyme specificity trypsin, maximum missed cleavage 1 , fixed modifications cysteine carbamidomethylation, variable modification methionine oxidation, precursor mass tolerance +/-3 kDa, fragment ion mass tolerance +/-0.4 kDa. Only Mascot hits with a false discovery rate (FDR) $\leq 0.05$ were taken into consideration.

Meta-analysis and subtractive data analysis. Proteins with at least two peptide matches were analysed further by comparing molecules that were only observed in urine samples from cancer patients with a database consisting of proteins found by other studies in urine, blood and kidney. This database was assembled from 136 publications, listing 146 tissue-specific datasets. The blood datasets covered plasma, serum and erythrocytes; the kidney studies were derived from analyses of cortex, medulla, epithelium, glomerulus, inner medullary collecting duct, mesangium, parenchyma, peroxisomal membrane, peroxisome, basolateral membrane vesicles, brush border membrane vesicles, urothelial mucosa and whole kidney; and urine datasets described either the whole or exosomal proteomes. All entries were then matched to the UniProt database, followed by clustering to individual (unique) entries by annotating splice and variant entries to common parent molecules and ultimately assigning each unique cluster an in-house specific accession number. Additionally, all proteins mapping to immunoglobulins were clustered into one generic cluster, as well as all proteins belonging to the Major Histocompatibility Complex (MHC). Merging and subtraction analysis was done using software written in-house. We also manually added our own functional classification tags to each molecular cluster, based on known properties of each molecule, giving an abridged view of proteome compositions.

\section{Results}

Urine samples were extracted from 21 healthy non-cancer controls and 41 patients with upper GI cancer $(n=41)$ (Table I). Of the 41 cancer patients, staging investigations demonstrated that at least $29(70.7 \%)$ had nodal or metastatic disease. We analysed all 62 urine samples by LC-MS/MS in the region 


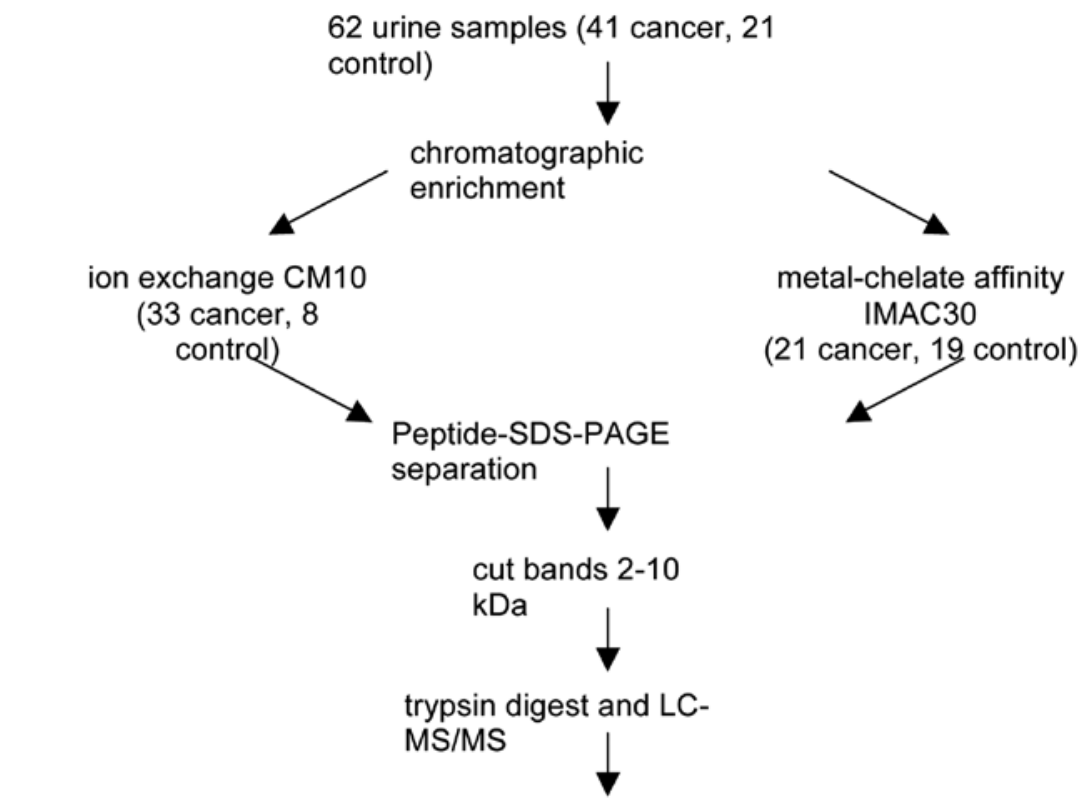

Mascot searching: 81 datasets, 35801 peptides, 7639 proteins

merging and thresholding (min 2 peptides, scores $>15)$ : 1228 unique proteins

removal of ambiguous entries: 1161 proteins

subtractive analysis 1: 745 proteins unique in cancer datasets

subtractive analysis 2: 268 proteins not found in external urinary non-cancer datasets

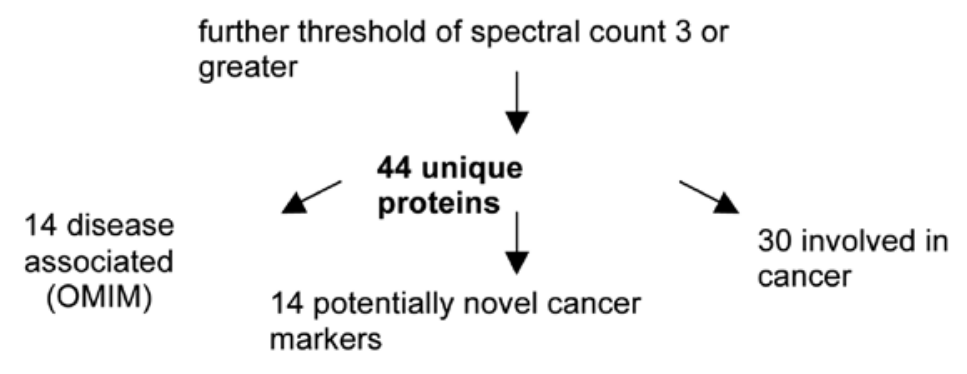

Figure 1. Flow-diagram of the steps involved to elucidate potential novel cancer markers.

of 2-10 kDa by chromatographic enrichment using either CM10, IMAC30, or both resin types individually, resulting in a total of 81 chromatographic enrichments, followed by gel analysis, tryptic digestion and mass spectrometry. All molecular weight regions cut from gels were identical in at least three samples from each cohort group, thus also allowing comparison of identified molecules on a gel-region by gel-region basis After data extraction by Mascot searching (resulting in 35,801 peptides covering 7,639 proteins) and applying discovery criteria of a FDR $\leq 0.05$ and a minimal Mascot score of 13 , the resulting 81 datasets were further analysed by merging all protein lists. This yielded 1,228 unique non-redundant entries (data not shown).
Additionally, all molecules relating to either immunoglobulins or MHC were also merged into two individual clusters since members of these two families are well known to show a great degree of hypervariability, and therefore they may skew any analysis towards single entries from those classes, since they are not expected to show any duplications across the datasets analysed in this study. The final list consisted of 1,161 molecular clusters. Furthermore, we re-classified all molecules in the datasets available by manually annotating every protein with a single molecular property or functionality tag as listed in the legend of Fig. 1. The properties or functionalities were assigned based on known properties of each individual protein, 

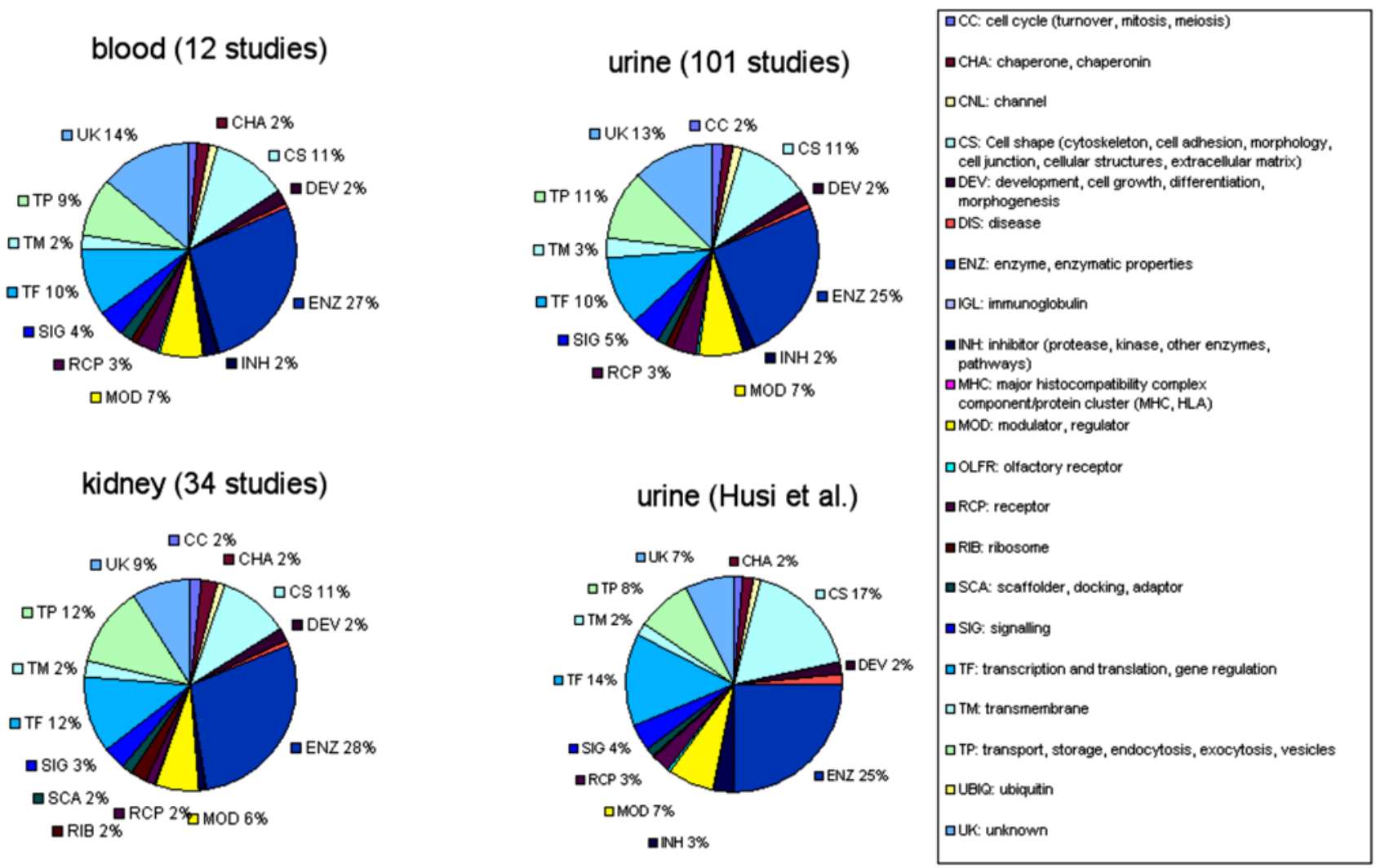

Figure 2. Composition of blood, urine, kidney and our datasets used in this study based on functional classifications. All merged datasets were analysed based on the functional description of each molecule assigned by our database and depicted as percentage pie-charts. The legend listing all possible classes is displayed on the right.

Table I. Demographics of the study cohort.

\begin{tabular}{lccc}
\hline & $\begin{array}{c}\text { Cancer } \\
(\mathrm{n}=41)\end{array}$ & $\begin{array}{c}\text { Control } \\
(\mathrm{n}=21)\end{array}$ & $\begin{array}{c}\text { Entire } \\
\text { cohort } \\
(\mathrm{n}=62)\end{array}$ \\
\hline Age (years) & $64(9.5)$ & $62.1(23.5)$ & $63.4(15.6)$ \\
Male (M:F) & $26: 15$ & $17: 04$ & $43: 19$ \\
Primary tumor origin & & & \\
Pancreas & 15 & N/A & \\
Oesophagus & 9 & & \\
OGJ & 7 & & \\
Stomach & 5 & & \\
Duodenum & 1 & & \\
Unknown & 4 & & \\
Histology & & & \\
Adenocarcinoma & 34 & N/A & \\
Squamous carcinoma & 3 & & \\
Unknown & 4 & & \\
\hline
\end{tabular}

Urine specimens were analysed from cancer patients $(n=41)$ and healthy controls $(\mathrm{n}=21)$. Data are presented as means with standard deviations in brackets. OGJ, oesophago-gastric junction.

either from original publications or derived from database annotations, such as enzyme nomenclatures, sequence homologies and domain analysis. The compositional analysis of the merged datasets of blood, urine and kidney proteomes, as well as our urinary dataset is shown in Fig. 2. It was clear that all merged datasets consist of $\sim 25 \%$ enzymes, $10 \%$ cell-shape molecules, $10 \%$ transcriptional or translational elements and $10 \%$ transport molecules. However, our novel dataset appeared to contain more cell-shape and transcriptional/translational proteins and less transport molecules, which may reflect an association with disease, rather than a general breakdown of cellular components.

The 1,161 molecules were then split into groups depending on whether they were observed in cancer urine samples, or urine from healthy individuals (Fig. 3A). The 745 proteins only found in cancer urine samples were then tagged and the entire dataset compared to data of 31,743 unmerged entries derived from 146 tissue-specific datasets from 137 publications (data not shown). This external data consisted of 9,707 merged entries, covering proteomic studies from urine, kidney and blood (Table II). A comparative analysis of our dataset with the three largest urinary proteome profiling datasets showed a $46 \%$ overlap of our data with the dataset from Kentsis et al (22), a $41 \%$ overlap with the study by Adachi et al (23), and a $21 \%$ with the urinary exosome dataset from Gonzales et al (24) (Fig. 3B). A global comparison between proteomes from urine, kidney and blood (Fig. 3C) demonstrated a slightly larger overlap of the urinary proteome with the kidney proteome than the blood proteome.

We then performed subtractive analysis on our urinary proteome data by eliminating any potential cancer candidate molecule if it was found in any of the urinary datasets 
A

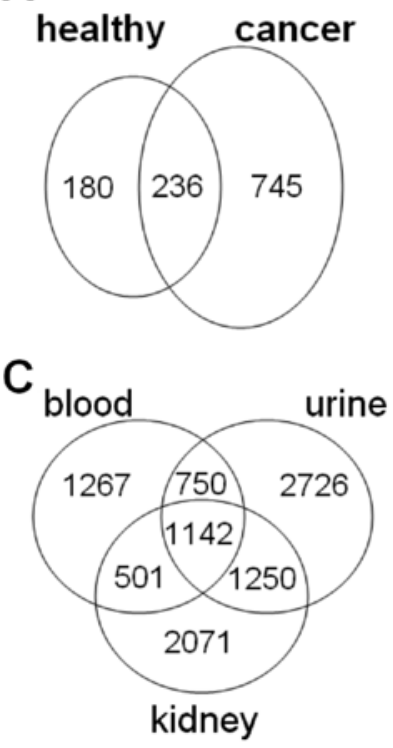

B

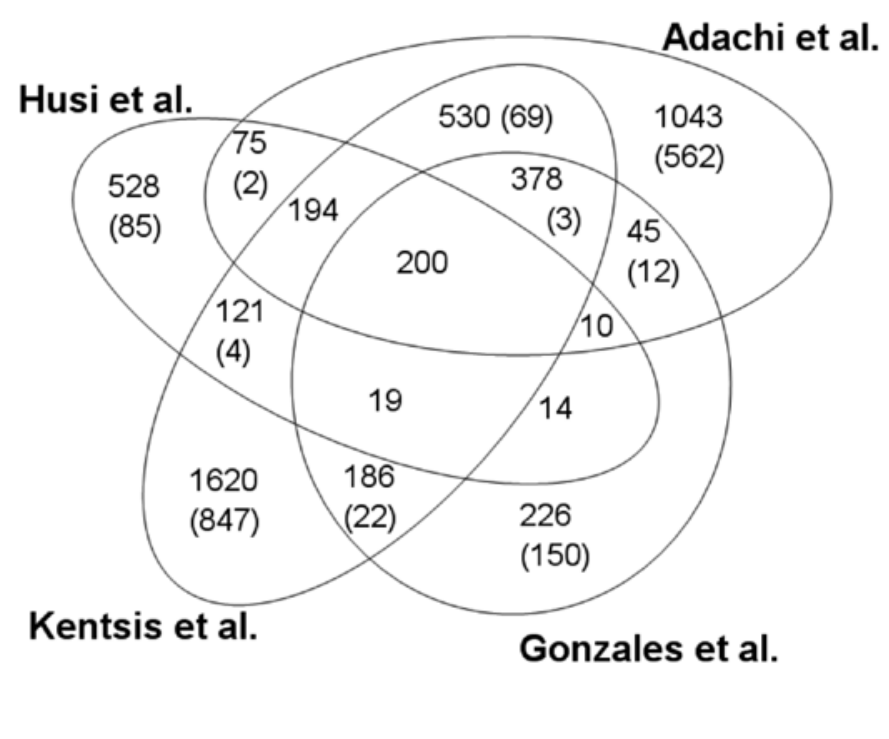

Figure 3. Venn diagrams of the meta-analysis to define potential cancer-associated molecules. Our dataset was analysed to define the overlap with datasets described in the literature. (A) Our dataset split into potential cancer markers by subtraction of molecules found in urine samples from healthy subjects. (B) Venn diagram of the four largest urinary datasets listed in the LSSR database, including the number of overlapping entries, and the number of questionable entries based on single peptide identification in brackets. (C) Overlap of all proteins found in urine with those found in blood and kidney, based on the datasets listed in the LSSR database.

Table II. Number of entries listed in the LSSR database for analysed samples derived from blood, urine and kidney.

\begin{tabular}{lccc}
\hline & $\begin{array}{c}\text { No. of entries } \\
\text { prior to merge }\end{array}$ & $\begin{array}{c}\text { Merged } \\
\text { entries }\end{array}$ & $\begin{array}{c}\text { No. } \\
\text { of studies }\end{array}$ \\
\hline Urine & 13,635 & 5,868 & 101 \\
Blood & 4,433 & 3,660 & 12 \\
Kidney & 13,675 & 4,964 & 34 \\
\hline
\end{tabular}

The number of entries by tissue type is given either as numbers derived directly from the studies analysed, or after merging all datasets based on unique identifiers assigned by our database.

unrelated to cancer. This reduced dataset of 268 proteins (data not shown) was further condensed by removing any entries which did not have a spectral count of at least two, resulting in 44 proteins, of which 24 were found uniquely in our study (in comparison to all other datasets), and 20 which were also found in the other tissues (Table III). All 44 of these proteins were then analysed by searching the Online Mendelian Inheritance in Man (OMIM) database for publications where these molecules were reported to be directly associated with human disease or cancer. Fourteen proteins were annotated in OMIM to be causative for a disease, and 30 were known to be involved in cancer.

\section{Discussion}

Proteomic large-scale analysis of tissues to define a cancer state can be time- and resource-consuming, especially in light of an unknown end-point. Therefore, it could be helpful to compare a novel dataset with known data in order to establish whether potential disease markers are observable, and thereby analyse a simplified dataset for the disease in question. This approach does not address the issue of quantitative comparisons, but it is rather a qualitative approach. However, the resulting list of potential candidate molecules will have a specificity of $100 \%$. Here, we test this hypothesis by applying a subtractive analysis method in conjunction with large-scale meta-analysis of urinary datasets to screen for potential novel cancer markers observable in human urine.

An initial comparison of functional profiles of urine, blood and kidney proteomes showed no major discernible difference between those datasets. This finding, in itself is not surprising, since it is expected that these systems should reflect an overall similar composition through a combination of immediate environment and source. Blood, containing a substantial amount of cells, is also expected to show a reasonably uniform functional composition profile compared with other tissues e.g. kidney. Our novel urinary dataset, having an expected bias towards an aberrant functional profile due to overexpressed molecules associated with disease, contains more molecules involved in cellular contacts, morphology and cytoskeletal aspects, as well as transcriptional/translational components, which may be directly linked to abnormal and uncontrolled cellular growth.

Comparison of our dataset with known non-cancer urinary proteomes yielded a set of only 44 molecules specific for our cancer data, of which $68 \%$ are already known to be involved in cancer. The functional profile of those 44 proteins in comparison to the merged urinary proteome profile showed mainly an enrichment of developmental proteins (5\%), signaling molecules (7\%) and, most strikingly, transcriptional/ translational proteins (20\%). The known cancer-associated molecules described have been suggested to be involved in hepatocellular carcinoma [ $\kappa$ actin (POTEKP) (25); BolA-like protein 2 (BOLA2) (26); fragile $\mathrm{X}$ mental retardation 1 protein $(F M R l)(27)]$; mammary 


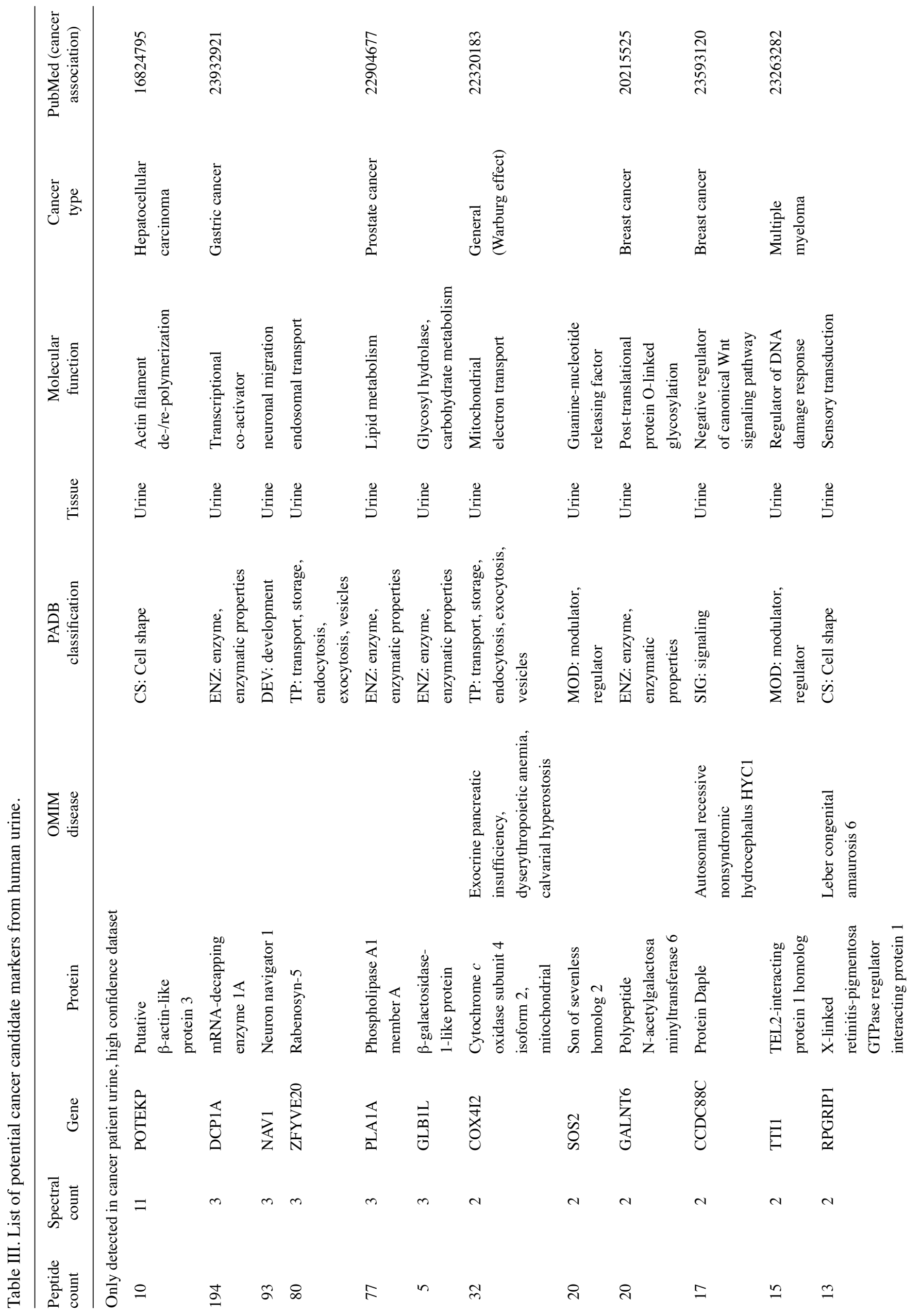




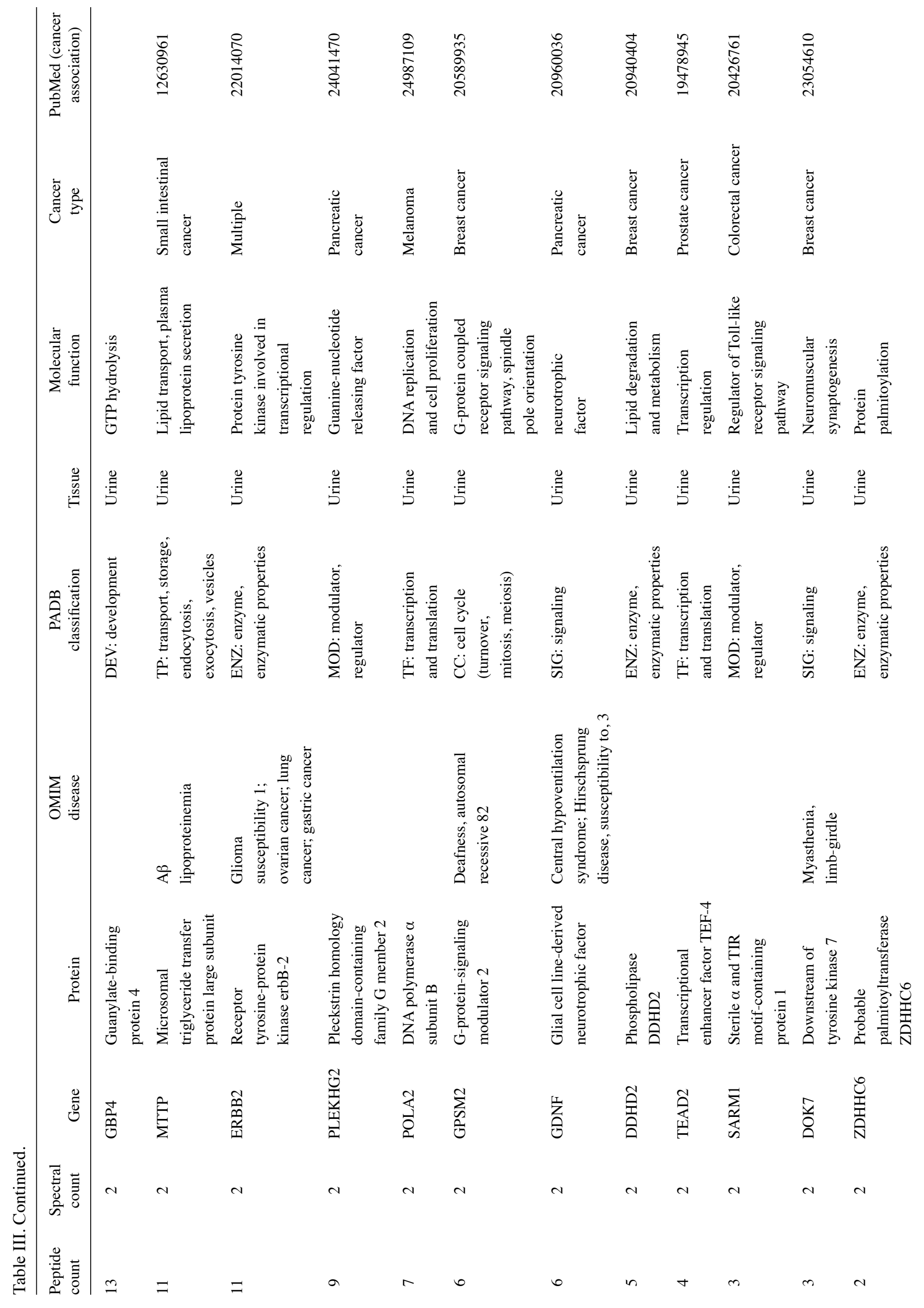




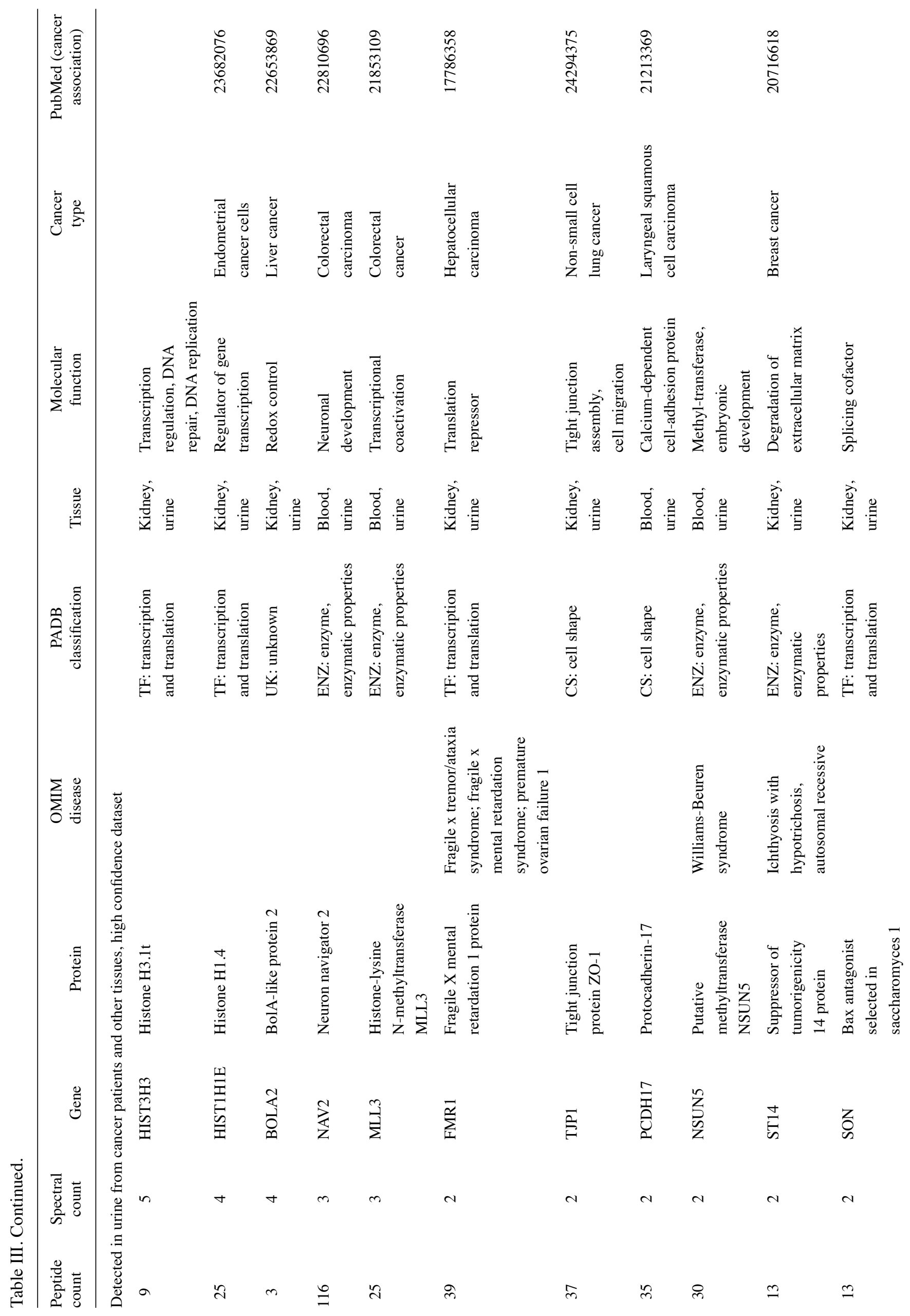




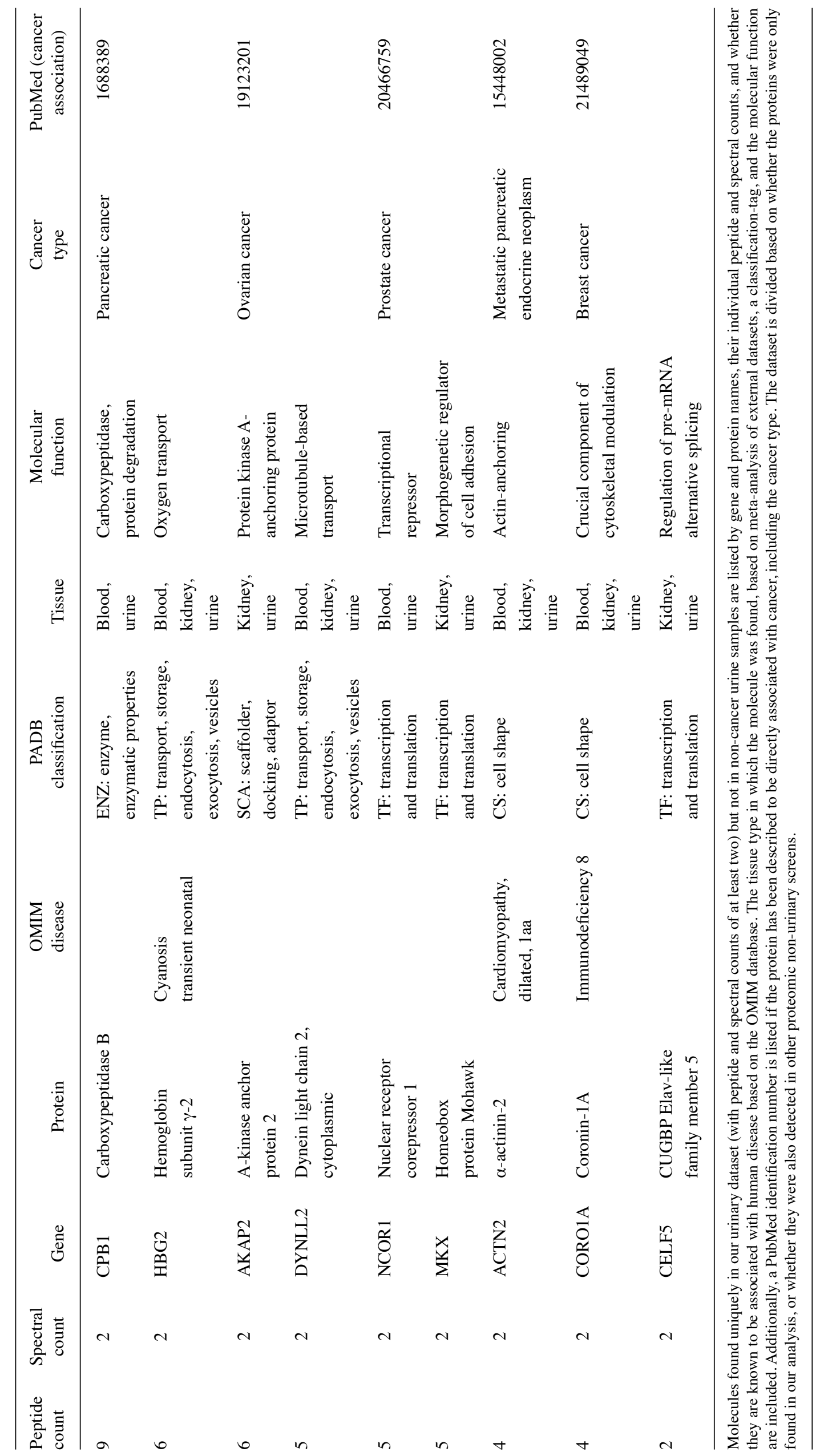


carcinogenesis [polypeptide $\mathrm{N}$-acetylgalactosaminyltrans ferase 6 (GALNT6) (28); protein Daple (CCDC88C) (29); G-protein-signaling modulator 2 (GPSM2) (30); phospholipase DDHD2 (DDHD2) (31); downstream of tyrosine kinase 7 (DOK7) (32); suppressor of tumorigenicity 14 protein (ST14) (33); coronin-1A (CORO1A) (34)], lung cancer [tight junction protein ZO-1 (TJP1) (35)], prostate cancer [phospholipase A1 member A (PLA1A) (36); transcriptional enhancer factor TEF-4 (TEAD2) (37); nuclear receptor corepressor 1 (NCOR1) (38)], ovarian cancer [A-kinase anchor protein 2 (AKAP2) (39)], colorectal cancer [sterile $\alpha$ and TIR motif-containing protein 1 (SARM1) (40); neuron navigator 2 (NAV2) (41); histone-lysine N-methyltransferase MLL3 (MLL3) (42)], pancreatic cancer [pleckstrin homology domain-containing family G member 2 (PLEKHG2) (43); glial cell line-derived neurotrophic factor $(G D N F)$ (44); carboxypeptidase B (CPB1) (45); $\alpha$-actinin-2 (ACTN2) (46)], gastric cancer [mRNA-decapping enzyme 1A (DCP1A) (47), a co-activator in TGF- $\beta$ signaling (48)], melanoma [DNA polymerase $\alpha$ subunit B (POLA2) (49)], multiple myeloma [TEL2-interacting protein 1 homolog (TTI1) (50)], endometrial cancer cells [Histone H1.4 (HIST1H1E (51)], laryngeal squamous cell carcinoma [protocadherin-17 (PCDH17) (52)], and adenocarcinoma [microsomal triglyceride transfer protein large subunit (MTTP) (53)]. Additionally, the latter protein was also described to be a pivotal element in the cancer-associated muscle-wasting disease cachexia (54). Some of these proteins may be differentially regulated across a range of different cancer types and may therefore represent key cancer markers. For example, receptor tyrosine-protein kinase erbB-2 (ERBB2) has been described to be a marker for various cancer types, such as gastroesophageal (55), breast (56), lung (57), gallbladder (58) and pancreatic cancer (59), as well as uterine serous adenocarcinoma (60), and others. Another known protein to be involved in cancer progression is the mitochondrial cytochrome $c$ oxidase subunit 4 isoform 2 (COX4I2), which is part of the Warburg effect, where cancer cells show higher propensity to produce lactate independent of oxygen presence or absence (61).

Of the proteins not previously described in association with cancer, transcription factor Bax antagonists selected in Saccharomyces 1 (SON), homeobox protein Mohawk (MKX) and CUGBP Elav-like family member 5 (CELF5) may represent other potential lead candidates in cancer stratification. Other important markers may include developmental molecules, such as guanylate-binding protein 4 GBP4, which is a negative regulator of virus-triggered cellular responses (62) and is involved in GTP hydrolysis, or neuron navigator NAV1, which has been reported to be a neuronal guidance molecule (63). However, its role in cancer or outside the neuronal environment remains to be elucidated.

In conclusion, we have demonstrated that a subtractive analysis of proteomic datasets can yield a number of potential diagnostic cancer targets in human urine. Further specific screening of urine, based on our findings, using, for example, an antibody-based approach, will establish whether our potential markers are associated with a general cancer status, or if they are specific for a defined cancer type such as pancreatic or esophageal cancer. Additionally, since the data in our database can easily be expanded to contain further datasets, there are other, as yet undefined diseases, which can be addressed by establishing and comparing a relatively small disease-specific dataset. This approach also has the advantage of rapid turnover and increased cost-effectiveness relating to large-scale analyses of tissue and cell proteomes for the discovery of novel molecular markers. In this regard, we are encouraging researchers to submit their published datasets to be incorporated in the LSSR database. All data will be freely available through the PADB portal at www.PADB.org.

\section{Acknowledgements}

We thank C.A. Greig, N.A. Stephens and H. Wackerhage for patient recruitment. Funding of this study was provided by the University of Edinburgh.

\section{References}

1. Good DM, Thongboonkerd V, Novak J, Bascands JL, Schanstra JP, Coon JJ, Dominiczak A and Mischak H: Body fluid proteomics for biomarker discovery: Lessons from the past hold the key to success in the future. J Proteome Res 6: 4549-4555, 2007.

2. Marshall T and Williams K: Two-dimensional electrophoresis of human urinary proteins following concentration by dye precipitation. Electrophoresis 17: 1265-1272, 1996.

3. Pieper R, Gatlin CL, McGrath AM, Makusky AJ, Mondal M, Seonarain M, Field E, Schatz CR, Estock MA, Ahmed N, et al: Characterization of the human urinary proteome: A method for high-resolution display of urinary proteins on two-dimensional electrophoresis gels with a yield of nearly 1400 distinct protein spots. Proteomics 4: 1159-1174, 2004.

4. Büeler MR, WiederkehrF and Vonderschmitt DJ: Electrophoretic, chromatographic and immunological studies of human urinary proteins. Electrophoresis 16: 124-134, 1995.

5. Spahr CS, Davis MT, McGinley MD, Robinson JH, Bures EJ, Beierle J, Mort J, Courchesne PL, Chen K, Wahl RC, et al: Towards defining the urinary proteome using liquid chromatographytandem mass spectrometry. I. Profiling an unfractionated tryptic digest. Proteomics 1: 93-107, 2001.

6. Cadieux PA, Beiko DT, Watterson JD, Burton JP, Howard JC, Knudsen BE,Gan BS, McCormick JK, Chambers AF, Denstedt JD, et al: Surface-enhanced laser desorption/ionization-time of flight-mass spectrometry (SELDI-TOF-MS): A new proteomic urinary test for patients with urolithiasis. J Clin Lab Anal 18: $170-175,2004$

7. Roelofsen H, Alvarez-Llamas G, Schepers M, Landman K and Vonk RJ: Proteomics profiling of urine with surface enhanced laser desorption/ionization time of flight mass spectrometry. Proteome Sci 5: 2, 2007.

8. Vanhoutte KJ, Laarakkers C, Marchiori E, Pickkers P, Wetzels JF, Willems JL, van den Heuvel LP, Russel FG and Masereeuw R: Biomarker discovery with SELDI-TOF MS in human urine associated with early renal injury: Evaluation with computational analytical tools. Nephrol Dial Transplant 22: 2932-2943, 2007.

9. Husi H, Stephens N, Cronshaw A, MacDonald A, Gallagher I, Greig C, Fearon KC and Ross JA: Proteomic analysis of urinary upper gastrointestinal cancer markers. Proteomics Clin Appl 5: 289-299, 2011.

10. Petri AL, Simonsen AH, Yip TT, Hogdall E, Fung ET, Lundvall L and Hogdall C: Three new potential ovarian cancer biomarkers detected in human urine with equalizer bead technology. Acta Obstet Gynecol Scand 88: 18-26, 2009.

11. Tsui KH, Tang P, Lin CY, Chang PL, Chang CH and Yung BY: Bikunin loss in urine as useful marker for bladder carcinoma. J Urol 183: 339-344, 2010.

12. Chen YT, Chen CL, Chen HW, Chung T, Wu CC, Chen CD, Hsu CW, Chen MC, Tsui KH, Chang PL, et al: Discovery of novel bladder cancer biomarkers by comparative urine proteomics using iTRAQ technology. J Proteome Res 9: 5803-5815, 2010.

13. Tan LB, Chen KT, Yuan YC, Liao PC and Guo HR: Identification of urine PLK2 as a marker of bladder tumors by proteomic analysis. World J Urol 28: 117-122, 2010.

14. Xue A, Scarlett CJ, Chung L, Butturini G, Scarpa A, Gandy R, Wilson SR, Baxter RC and Smith RC: Discovery of serum biomarkers for pancreatic adenocarcinoma using proteomic analysis. Br J Cancer 103: 391-400, 2010. 
15. Schröder C, Jacob A, Tonack S, Radon TP, Sill M, Zucknick M, Rüffer S, Costello E, Neoptolemos JP, Crnogorac-Jurcevic T, et al: Dual-color proteomic profiling of complex samples with a microarray of 810 cancer-related antibodies. Mol Cell Proteomics 9: 1271-1280, 2010.

16. Good DM, Zürbig P, Argilés A, Bauer HW, Behrens G, Coon JJ, Dakna M, Decramer S, Delles C, Dominiczak AF, et al: Naturally occurring human urinary peptides for use in diagnosis of chronic kidney disease. Mol Cell Proteomics 9: 2424-2437, 2010.

17. Zhang Y, Zhang Y, Adachi J, Olsen JV, Shi R, de Souza G, Pasini E, Foster LJ, Macek B, Zougman A, et al: MAPU: Max-Planck Unified database of organellar, cellular, tissue and body fluid proteomes. Nucleic Acids Res 35: D771-D779, 2007.

18. Li SJ, Peng M, Li H, Liu BS, Wang C, Wu JR, Li YX and Zeng R: Sys-BodyFluid: A systematical database for human body fluid proteome research. Nucleic Acids Res 37: D907-D912, 2009.

19. Agron IA, Avtonomov DM, Kononikhin AS, Popov IA, Moshkovskii SA and Nikolaev EN: Accurate mass tag retention time database for urine proteome analysis by chromatographymass spectrometry. Biochemistry (Mosc) 75: 636-641, 2010.

20. Carson JM, Okamura K, Wakashin H, McFann K, Dobrinskikh E, Kopp JB and Blaine J: Podocytes degrade endocytosed albumin primarily in lysosomes. PLoS One 9: e99771, 2014.

21. Collins MO, Yu L and Choudhary JS: Analysis protein complexes by $1 D$-SDS-PAGE and tandem mass spectrometry. Protocol Exchange, 2008. doi: 10.1038/nprot.2008.123.

22. Kentsis A, Monigatti F, Dorff K, Campagne F, Bachur R and Steen H: Urine proteomics for profiling of human disease using high accuracy mass spectrometry. Proteomics Clin Appl 3: 1052-1061, 2009.

23. Adachi J, Kumar C, Zhang Y, Olsen JV and Mann M: The human urinary proteome contains more than 1500 proteins, including a large proportion of membrane proteins. Genome Biol 7: R80, 2006.

24. Gonzales PA, Pisitkun T, Hoffert JD, Tchapyjnikov D, Star RA Kleta R, Wang NS and Knepper MA: Large-scale proteomics and phosphoproteomics of urinary exosomes. J Am Soc Nephrol 20: 363-379, 2009.

25. Chang KW, Yang PY, Lai HY, Yeh TS, Chen TC and Yeh CT: Identification of a novel actin isoform in hepatocellular carcinoma. Hepatol Res 36: 33-39, 2006.

26. Hunecke D, Spanel R, Länger F, Nam SW and Borlak J: MYC-regulated genes involved in liver cell dysplasia identified in a transgenic model of liver cancer. J Pathol 228: 520-533, 2012.

27. Liu Y, Zhu X, Zhu J, Liao S, Tang Q, Liu K, Guan X, Zhang J and Feng Z: Identification of differential expression of genes in hepatocellular carcinoma by suppression subtractive hybridization combined cDNA microarray. Oncol Rep 18: 943-951, 2007.

28. Park JH, Nishidate T, Kijima K, Ohashi T, Takegawa K, Fujikane T, Hirata K, Nakamura Y and Katagiri T: Critical roles of mucin 1 glycosylation by transactivated polypeptide $\mathrm{N}$-acetylgalactosaminyltransferase 6 in mammary carcinogenesis. Cancer Res 70: 2759-2769, 2010.

29. Long J, Zhang B, Signorello LB, Cai Q, Deming-Halverson S, Shrubsole MJ, Sanderson M, Dennis J, Michailidou K, Easton DF, et al: Evaluating genome-wide association study-identified breast cancer risk variants in African-American women. PLoS One 8: e58350, 2013

30. Fukukawa $C$, Ueda K, Nishidate $T$, Katagiri T and Nakamura $Y$ : Critical roles of LGN/GPSM2 phosphorylation by PBK/TOPK in cell division of breast cancer cells. Genes Chromosomes Cancer 49: 861-872, 2010

31. Yang ZQ, Liu G, Bollig-Fischer A, Giroux CN and Ethier SP: Transforming properties of 8p11-12 amplified genes in human breast cancer. Cancer Res 70: 8487-8497, 2010.

32. Heyn H, Carmona FJ, Gomez A, Ferreira HJ, Bell JT, Sayols S, Ward K, Stefansson OA, Moran S, Sandoval J, et al: DNA methylation profiling in breast cancer discordant identical twins identifies DOK7 as novel epigenetic biomarker. Carcinogenesis 34: 102-108, 2013.

33. Kauppinen JM, Kosma VM, Soini Y, Sironen R, Nissinen M, Nykopp TK, Kärjä V, Eskelinen M, Kataja V and Mannermaa A: ST14 gene variant and decreased matriptase protein expression predict poor breast cancer survival. Cancer Epidemiol Biomarkers Prev 19: 2133-2142, 2010.

34. Hattori N, Okochi-Takada E, Kikuyama M, Wakabayashi M, Yamashita S and Ushijima T: Methylation silencing of angiopoietin-like 4 in rat and human mammary carcinomas. Cancer Sci 102: 1337-1343, 2011
35. Ni S, Xu L, Huang J,Feng J, Zhu H, Wang G and Wang X: Increased ZO-1 expression predicts valuable prognosis in non-small cell lung cancer. Int J Clin Exp Pathol 6: 2887-2895, 2013.

36. Paulo P, Ribeiro FR, Santos J, Mesquita D, Almeida M, Barros-Silva JD, Itkonen H, Henrique R, Jerónimo C, Sveen A, et al: Molecular subtyping of primary prostate cancer reveals specific and shared target genes of different ETS rearrangements. Neoplasia 14: 600-611, 2012

37. Blum R, Gupta R, Burger PE, Ontiveros CS, Salm SN, Xiong X, Kamb A, Wesche H, Marshall L, Cutler G, et al: Molecular signatures of prostate stem cells reveal novel signaling pathways and provide insights into prostate cancer. PLoS One 4: e5722, 2009

38. Battaglia S, Maguire O, Thorne JL, Hornung LB, Doig CL, Liu S, Sucheston LE, Bianchi A, Khanim FL, Gommersall LM, et al: Elevated NCOR1 disrupts PPARalpha/gamma signaling in prostate cancer and forms a targetable epigenetic lesion. Carcinogenesis 31: 1650-1660, 2010 .

39. Quinn MC, Filali-Mouhim A, Provencher DM, Mes-Masson AM and Tonin PN: Reprogramming of the transcriptome in a novel chromosome 3 transfer tumor suppressor ovarian cancer cell line model affected molecular networks that are characteristic of ovarian cancer. Mol Carcinog 48: 648-661, 2009.

40. Quyun C, Ye Z, Lin SC and Lin B: Recent patents and advances in genomic biomarker discovery for colorectal cancers. Recent Pat DNA Gene Seq 4: 86-93, 2010.

41. Cancer Genome Atlas Network: Comprehensive molecular characterization of human colon and rectal cancer. Nature 487: 330-337, 2012.

42. Watanabe Y, Castoro RJ, Kim HS, North B, Oikawa R, Hiraishi T, Ahmed SS, Chung W, Cho MY, Toyota M, et al: Frequent alteration of MLL3 frameshift mutations in microsatellite deficient colorectal cancer. PLoS One 6: e23320, 2011

43. Shain AH, Salari K, Giacomini CP and Pollack JR: Integrative genomic and functional profiling of the pancreatic cancer genome. BMC Genomics 14: 624, 2013.

44. Liu H, Ma Q and Li J: High glucose promotes cell proliferation and enhances GDNF and RET expression in pancreatic cancer cells. Mol Cell Biochem 347: 95-101, 2011.

45. Fernstad R, Pousette A, Carlström K and Sköldefors H: A novel assay for pancreatic cellular damage: IV. Serum concentrations of pancreas-specific protein (PASP) in acute pancreatitis and other abdominal diseases. Pancreas 5: 42-49, 1990.

46. Hansel DE, Rahman A, House M, Ashfaq R, Berg K, Yeo CJ and Maitra A: Met proto-oncogene and insulin-like growth factor binding protein 3 overexpression correlates with metastatic ability in well-differentiated pancreatic endocrine neoplasms. Clin Cancer Res 10: 6152-6158, 2004.

47. Iio A, Takagi T, Miki K, Naoe T, Nakayama A and Akao Y: DDX6 post-transcriptionally down-regulates miR-143/145 expression through host gene NCR143/145 in cancer cells. Biochim Biophys Acta 1829: 1102-1110, 2013.

48. Bai RY, Koester C, Ouyang T, Hahn SA, Hammerschmidt M, Peschel C and Duyster J: SMIF, a Smad4-interacting protein that functions as a co-activator in TGFbeta signaling. Nat Cell Biol 4: 181-190, 2002

49. Lu YC, Yao X, Crystal JS, Li YF, El-Gamil M, Gross C, Davis L, Dudley ME, Yang JC, Samuels Y, et al: Efficient identification of mutated cancer antigens recognized by $\mathrm{T}$ cells associated with durable tumor regressions. Clin Cancer Res 20: 3401-3410, 2014.

50. Fernández-Sáiz V, Targosz BS, Lemeer S, Eichner R, Langer C, Bullinger L, Reiter C, Slotta-Huspenina J, Schroeder S, Knorn AM, et al: SCFFbxo9 and CK2 direct the cellular response to growth factor withdrawal via Tel2/Ttil degradation and promote survival in multiple myeloma. Nat Cell Biol 15: 72-81, 2013

51. Lee LR, Teng PN, Nguyen H, Hood BL, Kavandi L, Wang G, Turbov JM, Thaete LG, Hamilton CA, Maxwell GL, et al: Progesterone enhances calcitriol antitumor activity by upregulating vitamin D receptor expression and promoting apoptosis in endometrial cancer cells. Cancer Prev Res (Phila) 6: 731-743, 2013.

52. Giefing M, Zemke N, Brauze D, Kostrzewska-Poczekaj M, Luczak M, Szaumkessel M, Pelinska K, Kiwerska K, Tönnies H, Grenman R, et al: High resolution ArrayCGH and expression profiling identifies PTPRD and PCDH17/PCH68 as tumor suppressor gene candidates in laryngeal squamous cell carcinoma. Genes Chromosomes Cancer 50: 154-166, 2011.

53. Al-Shali K, Wang J, Rosen F and Hegele RA: Ileal adenocarcinoma in a mild phenotype of abetalipoproteinemia. Clin Genet 63: 135-138, 2003. 
54. Silvério R, Laviano A, Rossi Fanelli $\mathrm{F}$ and Seelaender $\mathrm{M}$ : L-Carnitine induces recovery of liver lipid metabolism in cancer cachexia. Amino Acids 42: 1783-1792, 2012.

55. Hjortland GO, Meza-Zepeda LA, Beiske K, Ree AH, Tveito S, Hoifodt H, Bohler PJ, Hole KH, Myklebost O, Fodstad O, et al: Genome wide single cell analysis of chemotherapy resistant metastatic cells in a case of gastroesophageal adenocarcinoma. BMC Cancer 11: 455, 2011.

56. Adachi R, Horiuchi S, Sakurazawa Y, Hasegawa T, Sato K and Sakamaki T: ErbB2 down-regulates microRNA-205 in breast cancer. Biochem Biophys Res Commun 411: 804-808, 2011.

57. Janku F, Garrido-Laguna I, Petruzelka LB, Stewart DJ and Kurzrock R: Novel therapeutic targets in non-small cell lung cancer. J Thorac Oncol 6: 1601-1612, 2011.

58. Goldin RD and Roa JC: Gallbladder cancer: A morphological and molecular update. Histopathology 55: 218-229, 2009.

59. Komoto M, Nakata B, Amano R, Yamada N, Yashiro M, Ohira M, Wakasa K and Hirakawa K: HER2 overexpression correlates with survival after curative resection of pancreatic cancer. Cancer Sci 100: 1243-1247, 2009.
60. Elsahwi KS and Santin AD: erbB2 overexpression in uterine serous cancer: A molecular target for trastuzumab therapy. Obstet Gynecol Int 2011: 128295, 2011.

61. Mazzio EA, Boukli N, Rivera N and Soliman KF: Pericellular $\mathrm{pH}$ homeostasis is a primary function of the Warburg effect: Inversion of metabolic systems to control lactate steady state in tumor cells. Cancer Sci 103: 422-432, 2012.

62. Hu Y, Wang J, Yang B, Zheng N, Qin M, Ji Y, Lin G, Tian L, $\mathrm{Wu} \mathrm{X}, \mathrm{Wu} \mathrm{L}$, et al: Guanylate binding protein 4 negatively regulates virus-induced type I IFN and antiviral response by targeting IFN regulatory factor 7. J Immunol 187: 6456-6462, 2011.

63. Maes T, Barceló A and Buesa C: Neuron navigator: A human gene family with homology to unc-53, a cell guidance gene from Caenorhabditis elegans. Genomics 80: 21-30, 2002. 